\title{
Results and Complications of Conventional Repair of Bullous Retinal Detachment Using Posterior Segment Air Injection
}

\author{
B. C. LITTLE, ${ }^{*}$ D. V. INGLESBY, ${ }^{*}$ D. WONG, $\dagger$ and A. H. CHIGNELL* \\ London and Liverpool
}

\begin{abstract}
Summary
The aims of this retrospective study were to determine the outcome of retinal detachment repair using the drainage, air injection, cryotherapy and explant surgical sequence ('D-ACE' technique) for bullous retinal detachments and also to identify the complications attributable to the injection of the gas. The D-ACE technique was used to repair 206 detachments over a ten year period of which $138(67 \%)$ were successfully re-attached with a single operation.

The sub-group of these patients $(n=66)$ with bullous retinal detachments who would be considered suitable for repair using the technique of pneumoretinopexy (PR) showed a single operation success rate of $85 \%$ after D-ACE.

Complications attributable to the gas injection occurred in 18 eyes $(8.5 \%)$. In only four of these $(\mathbf{1 . 9} \%)$ did retinal surgery ultimately fail as a result of complications caused by injection of the gas, which represents $10 \%$ of all the failures.

The results of this series show that the serious complication rate from injecting air into the vitreous cavity is low and that the success rate for treating relatively uncomplicated bullous retinal detachments using the D-ACE technique compares favourably with the results of other published series using either the D-ACE procedure or pneumoretinopexy.
\end{abstract}

Gas injection into the vitreous cavity has been practised for many years, ${ }^{1,2}$ and has increased in popularity since the expanding gases became available.

Air injection has been used in combination with external drainage, cryotherapy and scleral buckling (the D-ACE surgical sequence $^{3}$ ). The main objective of this procedure is to replace the break against the pigment epithelium to ensure accurate placement of the buckle and of the cryosurgical adhesion for the treatment of bullous retinal detachment. More recently, expanding gases have been used in a procedure without scleral buckling or drainage of sub-retinal fluid (pneumoretinopexy (PR)). This technique was originally used for selected uncomplicated cases, ${ }^{4-7}$ but has since been applied to more complex detachments. ${ }^{8-12}$

In order to assess the relative efficacy of D-ACE and PR and to determine the complications attributable to intra-vitreal air injection we reviewed the records of 206 patients who had undergone retinal detachment repair using the D-ACE procedure. We selected a sub-group of these patients in order to pro-

* Department of Ophthalmology, St Thomas' Hospital, London SE1 7EH.

$\uparrow$ St Pauls Eye Hospital, Old Hall St, Liverpool L3 9PF.

Correspondence to: Mr. A. H. Chignell, South Wing Eye Department, St Thomas' Hospital, London SE1 7EH. 
Table I Surgical results of $D-A C E$

\begin{tabular}{lrccrr}
\hline Group parameter & $\begin{array}{l}\text { Number } \\
\text { in group }\end{array}$ & \% total & $\begin{array}{c}\text { Successful with } \\
\text { single operation }\end{array}$ & $\begin{array}{c}\text { Successful after } \\
\text { re-operation }\end{array}$ & Overall success \\
\hline Total & $206 / 206$ & 100 & $138(67 \%)$ & $28(14 \%)$ & $166(81 \%)$ \\
Aphakic & $38 / 206$ & 18 & $15(40 \%)$ & $7(18 \%)$ & $22(58 \%)$ \\
PVR & $47 / 206$ & 23 & $23(49 \%)$ & $2(4 \%)$ & $25(53 \%)$ \\
Previous surgery & $51 / 206$ & 25 & $31(61 \%)$ & $7(14 \%)$ & $38(75 \%)$ \\
No breaks found & $23 / 206$ & 11 & $10(44 \%)$ & $3(13 \%)$ & $13(57 \%)$ \\
Suitable for PR:* & $66 / 206$ & 32 & $56(85 \%)$ & $8(12 \%)$ & $64(97 \%)$ \\
\hline
\end{tabular}

${ }^{*}=$ phakic, no previous surgery, no PVR and breaks within upper 120 degrees

duce a yardstick against which the results of pneumoretinopexy could be measured, and to draw attention to the complications of air injection.

\section{Method}

A retrospective record review of patients admitted to St Thomas' Hospital, London, over ten years and to St Paul's Hospital, Liverpool over the past two years revealed 1,500 cases of retinal detachment repaired using conventional surgery of which 206 $(14 \%)$ had been repaired using the D-ACE technique. Those who had undergone previous vitrectomy were excluded. All these cases were judged to be unsuitable for a nondrainage operation due to the presence of deep sub-retinal fluid between the break(s) and the pigment epithelium. Pro-forma sheets detailing all clinical and operative findings were completed during the in-patient admission. The relevant data were selected from these forms and transferred into a database file (dBase III Plus release 3, Ashton Tate Ltd) from which all the results were computed.

\section{Results}

The group under study comprised 206 (108 male, 98 female) patients whose mean age at operation was 53 years and for whom follow-up continued for an average of 21 months. In $12 \%$ of patients, less than six months had elapsed post-operatively when the study began. The follow-up period of the remaining $88 \%$ was at least 6 months.

\section{Preoperative findings}

The refractive error of the majority of the patients $(53 \%)$ was between zero and minus six dioptres: $17 \%$ were high myopes and $18 \%$ were aphakic. Only 5\% were hypermetropic and in $7 \%$ the refractive error was unspecified.

Seventy-four percent had not undergone previous detachment surgery, 20\% had had one operation whilst only $4 \%$ had undergone more than one operation. In $2 \%$ the surgical history was unspecified.

A single retinal break was found in $52 \%$ of eyes. Multiple breaks were found in $37 \%$ and no break was found in $11 \%$.

Proliferative vitreoretinopathy (PVR) was present in $23 \%$ of eyes. The grade was not specified in $13 \%$ but was less than or equal to grade $\mathrm{C} 2$ in the remaining $10 \%$. Judging from the retinal drawings of those unspecified, no PVR of greater than grade $\mathrm{C} 2$ was found.

\section{Operative outcome}

Table I documents the success rates using D-ACE for the whole group and for five selected sub-groups. Four of these five show worse results than for the whole group for both the single and re-operation success rates. These sub-groups comprise aphakes, those with PVR of grade C2 or less, those who have had previous surgery and those in which no retinal breaks were found.

The selection criteria for the fifth sub-group were:

(1) Phakic eyes

(2) No previous surgery

(3) No PVR

(4) Retinal breaks within the upper 120 degrees

This group showed the best prognosis with a single operation success rate of $85 \%$ improving after re-operation to $97 \%$. This sub-group 
has been advocated to be the most suitable for pneumoretinopexy.

\section{Surgical results of $D-A C E$}

Complications of air injection.

We found that complications attributable to the air injection occurred in 19 eyes $(8.5 \%)$.

In three eyes multiple air bubbles formed producing a 'fish-egg' appearance in the vitreous and obscuring the view. The air in one case subsequently tracked beneath the retina.

In another three eyes injection of an excessive amount of air caused problems -in one case a catastrophic rise in intra-ocular pres. sure requiring paracentesis and in the other two vitreo-retinal incarceration at the drain site.

In six eyes the air appeared in the wrong place-under the retina in three cases, beneath the choroid in one case and in the anterior chamber in two aphakic eyes.

Injection site complications occurred in five eyes: haemorrhage extending into the vitreous in two eyes, air leakage in two eyes and vitreous incarceration in one eye.

There was one case of endophthalmitis in which the injection was the presumed cause and one case of puncture of a retinal bulla by the needle tip.

\section{Discussion}

Of the whole group, $67 \%(n=138)$ were cured with a single operation. A further $14 \%$ $(n=28)$ were re-attached at re-operation giving an overall success rate of $81 \%$ $(n=166)$. These patients comprise a relatively unselected and heterogeneous group as far as the nature and complexity of their retinal detachments are concerned. Thus 25\% had some degree of PVR (up to grade C2), $18 \%$ were aphakic, no breaks were found in $11 \%, 2.5 \%$ had a giant break, and $2 \%$ had macular holes. All these factors are known to reduce the chance of success of retinal detachment surgery. The earlier cases in this series were operated on at a time when the indications for pars plana vitrectomy had not been clearly established and it is now clear that the D-ACE procedure would not currently be considered appropriate for some of these cases.

A more highly selected sub-group which showed the highest success rate comprised eyes that were phakic, had not undergone previous surgery, did not have PVR preoperatively and in which the retinal breaks were positioned within the upper $120^{\circ}$. Of this group $(n=66), 85 \%$ were permanently reattached after one operation and a further $12 \%$ flattened following re-operation resulting in a final success rate of $97 \%$. These criteria were deliberately chosen in order to provide a comparable group of patients who would be considered suitable for pneumoretinopexy.

The results of this series show that the success rate for treating relatively uncomplicated but bullous retinal detachments using the D-ACE technique compares favourably with the results of other published series.

However, it is not possible to find out from the PR series how many of the reported cases were bullous under the break and how many had slight SRF under the break: an important distinction since it is quite possible that many of the latter cases could have been treated simply by a non-drainage approach.

We found that complications resulting from the injection of air occurred in 19 eyes $(8.5 \%)$ as described. They were of clinical significance in only six eyes. Of these, two were successfully treated with further surgery but four eventually failed. Of these four, two were related to overfill with air; one resulting in central retinal artery occlusion requiring paracentesis which led to massive choroidal haemorrhage, and the second developed purse-string tractional retinal detachment following vitreous incarceration in the injection site. Of the remaining two failures, one was due to post-operative endophthalmitis and the other was caused by air entering the subretinal space via a large break.

We did not find any new retinal breaks after air injection as has been reported following the injection of expanding gases. ${ }^{15-20}$

PVR up to grade C2 was present in $23 \%$ of eyes preoperatively. The prognosis for eyes with pre-existing PVR repaired using D-ACE was found to be poor with a success rate of only $54 \%$ including re-operations.

PVR developed de novo in $9 \%$ of eyes in which the D-ACE procedure had failed and this figure falls within the empirical normal 
Table II Results in comparable groups using $D$-ACE or pneumoretinopexy $(P R)$

\begin{tabular}{lccc}
\hline Author & Technique & Number & $\begin{array}{c}\text { Success rate } \\
\text { after single } \\
\text { operation }\end{array}$ \\
\hline Stanford (14) & D-ACE & 25 & $96 \%$ \\
Gilbert (3) & D-ACE & 50 & $90 \%$ \\
Little & D-ACE & 66 & $85 \%$ \\
Hilton (6) & PR & 20 & $90 \%$ \\
Hilton (7) & PR & 100 & $84 \%$ \\
Algvere (16) & PR & 35 & $83 \%$ \\
\hline
\end{tabular}

range of between $5-10 \%$. We found no evidence to suggest that the injection of air initiated development of PVR and it was impossible to determine retrospectively if air injection promoted the progression of preexisting membrane since there were too many unmatched variables in this group which may have independently contributed towards accelerated membrane formation (e.g. extent of cryotherapy, previous surgery, degree of uveitis) (Table II).

The results of this series show that the serious complication rate from injecting air into the vitreous cavity is low and that the success rate for treating relatively uncomplicated retinal detachments using the D-ACE procedure compares favourably with the results of other published series (Table II) particularly as the PR series probably contained many simple cases where SRF depth under the break was slight.

\footnotetext{
References

${ }^{1}$ Ohm J: Uber die Behandlung der Netzhautablosung durch operative Entleerung der subretinalen Flussigkeit und Einspritzung von Luft in den Glaskorper. Graefes Arch Clin Exp Ophthalmol 1911, 79: 442-50.

${ }^{2}$ Rosengren B: Cases of retinal detachment treated with diathermy and injection of air into the vitreous body. Acta Ophthalmol (Kbh) 1938, 16: $3-42$.

${ }^{3}$ Gilbert C and Macleod D: D-ACE surgical sequence for selected bullous retinal detachments. $\mathrm{Br} J$ Ophthalmol 1985, 69: 733-6.

${ }^{4}$ Norton EWD: Intraocular gas in the management of selected retinal detachments. Trans Am Acad Ophthalmol Otolaryngol 1973, 77: 85-98.

${ }^{5}$ Lincoff H, Coleman DJ, Kreissig I et al: The perflu-
}

orocarbon gases in the treatment of retinal detachment Ophthalmology 1983, 90: 546-51.

${ }^{6}$ Hilton GF and Grizzard WS: Pneumatic Retinopexy: a two-step out-patient operation without conjunctival incision. Ophthalmology 1986, 93: 626-41.

${ }^{7}$ Hilton GF, Kelly NE et al: Pneumatic Retinopexy; a collaborative report on the first 100 cases. Ophthalmology 1987, 94: 307-12.

${ }^{8}$ Schepens CL and Freeman HM: Current management of giant retinal breaks. Trans Am Acad Ophthalmol Otolaryngol 1967, 71: 474-87.

${ }^{9}$ Machemer R: Massive periretinal proliferation; a logical approach to treatment. Trans Am Ophthalmol Soc 1977, 75: 556-58.

${ }^{10}$ Kreissig I, Stanowsky A, Lincoff H, Richard G: The treatment of difficult retinal detachments with an expanding gas bubble without vitrectomy. Graefes Arch Clin Exp Ophthalmol 1986, 224: $51-4$.

${ }^{11}$ Kreissig I, Lincoff H, Stanowsky A: The treatment of giant tear detachments using retrohyaloidal perfluorocarbon gases without drainage or vitrectomy. Graefes Arch Clin Exp Ophthalmol 1987, 225: 94-8.

${ }^{12}$ McAllister IL, Zegarra H, Meyers SM, Gutman FA: Treatment of retinal detachments with multiple breaks by pneumatic retinopexy. Arch Ophthalmol 1987, 105: 913-16.

${ }^{13}$ Tornambe PE: Diagnostic and Surgical Techniques-Pneumatic Retinopexy Surv Ophthalmol 1988, 32: 270-81.

${ }^{14}$ Stanford MR and Chignell AH: Surgical treatment of superior bullous rhegmatogenous retinal detachments. Br J Ophthalmol 1985, 69: 729-32.

${ }^{15}$ Johnston PB, Maguire CJF, Logan WC: Failed retinal surgery caused by intraocular gas injection. Br J Ophthalmol 1988, 72: 322-5.

${ }^{16}$ Algvere P, Hallnas K, Palmqvist B: Success and complications in pneumatic retinopexy. $A m J$ Ophthalmol 1988, 106: 400-4.

${ }^{17}$ Dreyer RF: Sequential retinal tears attributed to intraocular gas. Am J Ophthalmol. 1986, 102: 276.

${ }^{18}$ Yeo JH, Vidaurri-Leal J, Glaser BM: Extension of retinal detachments as a complication of pneumatic retinopexy. Arch Ophthalmol 1986, 104: 1161-3.

${ }^{19}$ Poliner LS et al: New retinal detachment after pneumatic retinopexy. Ophthalmology 1987, 94: 315-18.

${ }^{20}$ Freeman WR, Lipson BK, Morgan CM, Liggett PE: New posteriorly located retinal breaks after pneumatic retinopexy. Ophthalmology 1988, 95: 14-18.

${ }^{21}$ Hilton GF, Kelly NE, Tornambe PE: Extension of retinal detachment as a complication of pneumatic retinopexy (letter). Arch Ophthalmol 1987, 105: 168 . 